UCRL-JC-125891

PREPRINT

\title{
Hybrid and Conventional Hydrogen Engine Vehicles that Meet EZEV Emissions
}

\author{
S. M. Aceves \\ J. R. Smith
}

This paper was prepared for submittal to the 1997 Society of Automotive Engineers International Congress and Exposition

Detroit, Michigan

February 24-27, 1997

December 10, 1996

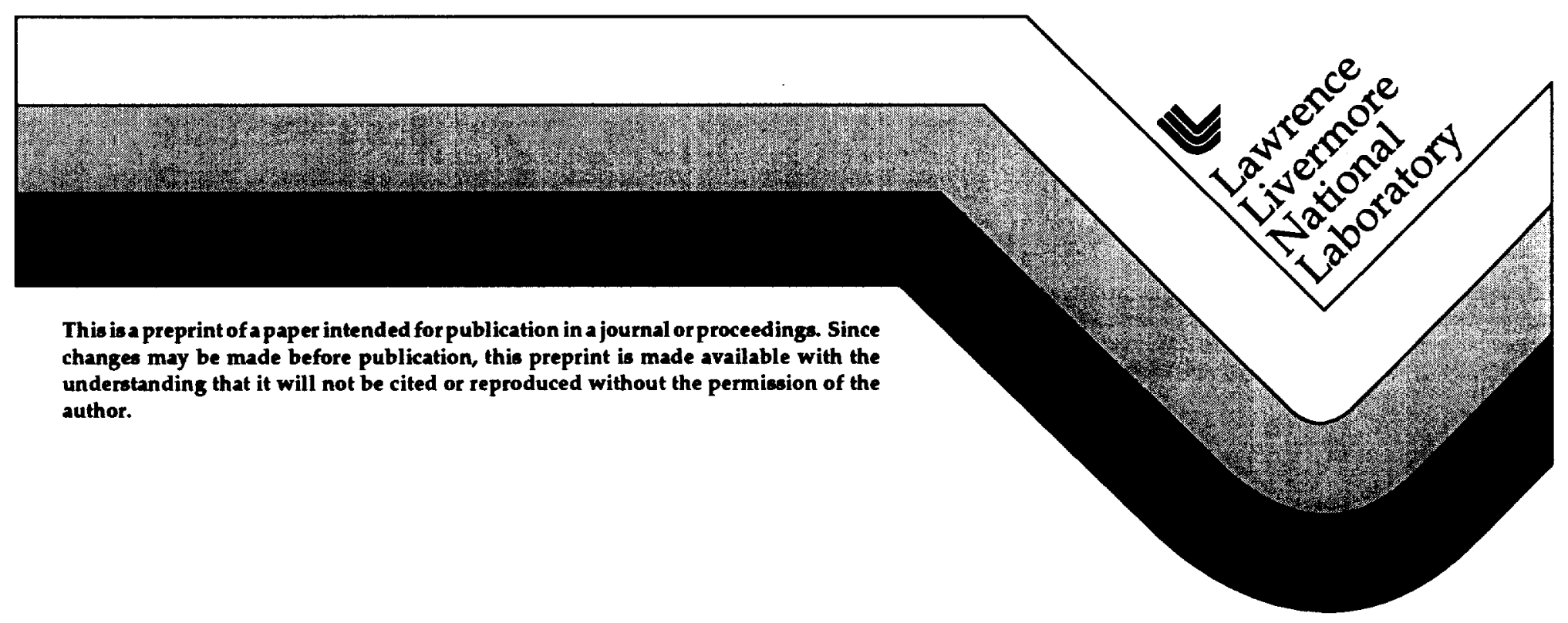




\section{DISCLAIMER}

This document was prepared as an account of work sponsored by an agency of the United States Government. Neither the United States Government nor the University of California nor any of their employees, makes any warranty, express or implied, or assumes any legal liability or responsibility for the accuracy, completeness, or usefulness of any information, apparatus, product, or process

disclosed, or represents that its use would not infringe privately owned rights. Reference herein to any specific commercial product, process, or service by trade name, trademark, manufacturer, or otherwise, does not necessarily constitute or imply its endorsement, recommendation, or favoring by the United States Government or the University of California. The views and opinions of authors expressed herein do not necessarily state or reflect those of the United States Government or the University of California, and shall not be used for advertising or product endorsement purposes. 


\title{
Hybrid and Conventional Hydrogen Engine Vehicles that Meet EZEV Emissions*
}

\author{
Salvador M. Aceves and J. Ray Smith
}

\begin{abstract}
Hydrogen-fueled, spark-ignited, homogeneous-charge engines offer an alternative for providing Equivalent Zero Emission Vehicle (EZEV) levels, along with a range and performance comparable to today's automobiles. Hydrogen in a spark-ignited engine can be burned at very low equivalence ratios, so that $\mathrm{NO}_{\mathrm{x}}$ emissions can be reduced to less than $10 \mathrm{ppm}$ without a catalytic converter or EGR. HC and $\mathrm{CO}$ emissions may result from oxidation of engine oil, but by proper design are negligible (a few ppm). Lean operation also results in increased indicated efficiency due to the thermodynamic properties of the gaseous mixture contained in the cylinder and due to reduced heat transfer. The high effective octane number of hydrogen allows the use of a high compression ratio, further increasing engine efficiency.

In this paper, a time-dependent engine model is used for predicting hydrogen engine efficiency and emissions. The model uses basic thermodynamic equations for the compression and expansion processes, along with an empirical correlation for heat transfer, to predict engine indicated efficiency. A friction correlation and a supercharger/turbocharger model are then used to calculate brake thermal efficiency. The model is validated with many experimental points obtained in a recent evaluation of a hydrogen research engine.
\end{abstract}

The validated engine model is then used to calculate fuel economy and emissions for three hydrogenfueled vehicles: a conventional, a parallel hybrid, and a series hybrid. All vehicles use liquid hydrogen as a fuel. The hybrid vehicles use a flywheel for energy storage. Comparable ultra capacitor or battery energy storage performance would give similar results. This paper analyzes the engine and flywheel sizing requirements for obtaining a desired level of performance. The results indicate that hydrogen lean-burn spark-ignited engines can provide a high fuel economy and Equivalent Zero Emission Vehicle (EZEV) levels in the three vehicle configurations being analyzed.

\section{INTRODUCTION}

Hydrogen has very special properties, including a very high laminar flame speed, a high effective octane number, and no toxicity or ozone-forming potential [1]. Homogeneous-charge spark-ignited piston engines can be designed to take advantage of these characteristics. The high laminar flame speed allows the use of very low equivalence ratios (as low as 0.2 ), reducing $\mathrm{NO}_{\mathrm{x}}$ emissions to nearzero levels without requiring a catalytic converter, that may deteriorate with time. The use of low equivalence ratios also increases the indicated efficiency, and reduces the need for throttled operation [2]. The engine can have a high compression ratio, due to the high octane number of hydrogen.

This paper analyzes the applicability of hydrogen homogeneous-charge spark-ignited piston engines to Equivalent Zero Emission Vehicles (EZEV). ${ }^{1}$ The analysis uses an engine model that is calibrated to match the data obtained in a recent experiment [4], and a vehicle simulation code that can be applied to

\footnotetext{
'Equivalent Zero Emission Vehicles are defined here as those that generate less emissions when operating inside the Los Angeles Basin than the power plant emissions generated as a result of electric car operation. These emission levels are being considered for approval by CARB [3]. Proposed EZEV levels are: $0.0025 \mathrm{~g} / \mathrm{km}(0.004$ $\mathrm{g} / \mathrm{mi}) \mathrm{NMHC} ; 0.11 \mathrm{~g} / \mathrm{km}(0.17 \mathrm{~g} / \mathrm{mi}) \mathrm{CO}$; and $0.012 \mathrm{~g} / \mathrm{km}(0.02 \mathrm{~g} / \mathrm{mi}) \mathrm{NO}_{\mathrm{x}}$. These values are equal to one tenth of CARB ULEV standards.
} 
calculating fuel economy and emissions [5]. The engine model is used to generate optimized engine performance maps for supercharged operation, with constraints of limited $\mathrm{NO}_{\mathrm{x}}$ emissions, limited manifold pressure and maximum mean piston speed.

The engine maps are applied for predicting fuel economy and emissions for a conventional vehicle, a parallel hybrid vehicle, and a series hybrid vehicle. All these vehicles use liquid hydrogen as a fuel, and hybrid vehicles use a flywheel for energy storage. Although liquid hydrogen is not a common fuel, its safe use has been demonstrated by BMW for a number of years [6]. The parallel hybrid operates almost identically as a conventional car, with a flywheel for regenerative braking and for complementing the power of the engine during sudden accelerations. The series hybrid vehicle engine operates in an on-off mode to keep the flywheel charged. When the engine is off, the flywheel provides all the energy for transportation and accessories.

\section{ENGINE MODEL}

The engine model uses first principles and correlations to predict piston engine efficiency and power output. The engine model is a lumped (zero-dimensional), time-dependent model which solves the basic differential equations for the compression and power strokes. An empirical equation [7] is used for calculating heat release. The heat release equation has three free parameters which determine the shape and duration of the heat release function as a function of crank angle. These three parameters are determined for each experimental run by using an optimizer [8]. The optimizer finds the combination of the three parameters that minimizes the differences between the experimental pressure trace and the pressure trace calculated by the model. The results have been very satisfactory. The relative errors in matching the pressure traces at MBT timing have been of the order of $0.5 \%$, with a maximum error of $1 \%$ over all engine speeds, equivalence ratios and manifold pressures.

The engine model uses Woschni's correlation [9] to estimate engine heat transfer. It was found during the analysis that the heat transfer correlation underpredicts heat transfer losses. Woschni's correlation includes two constants, $\mathrm{C}_{1}$ and $\mathrm{C}_{2}$, which determine the effect of fluid flow on heat transfer. To obtain a better match with the experimental data, the original values of these two constants were multiplied by 1.8. The increased heat transfer coefficient reduces the predicted engine efficiency by about $1 \%$ with respect to the engine model with the unmodified Woschni's correlation. It is noted that Woschni's correlation has been applied in the past to diesel and gasoline engines, so some adjustment to the coefficient is to be expected as a result of using a different fuel. It is encouraging that the adjustments to those coefficients, which are not directly proportional to heat transfer, have a small effect on engine efficiency.

The engine model includes a friction model and a supercharger/turbocharger model to predict brake thermal efficiency. The friction model uses a detailed correlation [10]. Supercharger and turbocharger performance are calculated by using a thermodynamic model and assuming a constant $(0.7)$ isentropic efficiency for both the turbine and the compressor. Selection of a supercharger to optimally increase the power as required to meet the power demands is outside the current experience of the authors. However, a detailed supercharger map could be incorporated into the model if further refinement is desired. A water-cooled intercooler is assumed with a thermal effectiveness of 0.7 . Based on reported data for typical engines [2], volumetric efficiency is assumed to vary linearly from $85 \%$ at low engine speeds, to a maximum of $95 \%$ at $4000 \mathrm{rpm}$, down to $90 \%$ at $5000 \mathrm{rpm}$.

The engine model is validated by comparing the calculated results with the experimental results obtained in a recent engine evaluation [4]. The engine used in the experimental evaluation is an Onan engine which was modified by incorporating a head containing two spark plugs, along with the original two valves. The intake valve was modified with a $1.5 \mathrm{~mm}$ high, 180 degree shrowd to add some swirl which resulted in improved efficiency. The combustion chamber is a simple right circular cylinder with no squish and a flat top piston. This geometry has been shown to be the most efficient shape for 
reducing heat transfer losses in lean-burn engines [11]. Engine characteristics are listed in Table 1, along with the range of conditions used in the experiment.

Table 1. Modified Onan engine characteristics and experimental conditions.

Bore, $\mathrm{mm}$

Stroke, $\mathrm{mm}$

Displacement, $\mathrm{cm}^{3}$

Geometric compression ratio

Experimental range for equivalence ratio

Experimental range for engine speed, $\mathrm{rmm}$

Experimental range for volumetric efficiency, \%
82.55

92.08

493.0

14.0

$0.2-0.5$

1200-1800

$90-215$

Figure 1 shows a comparison between experimental and calculated indicated efficiencies, as a function of equivalence ratio, for all the experimental points at MBT timing. Engine speeds are indicated with different symbols. A 0.39 equivalence ratio was selected for most supercharged runs. Figure 1 shows gross indicated efficiency, defined as including only work done on the piston during the compression and expansion strokes [2]. The experimental engine was supercharged by directly supplying the fuel and air from pressurized sources. Pumping work is accounted for as a part of the engine friction model.

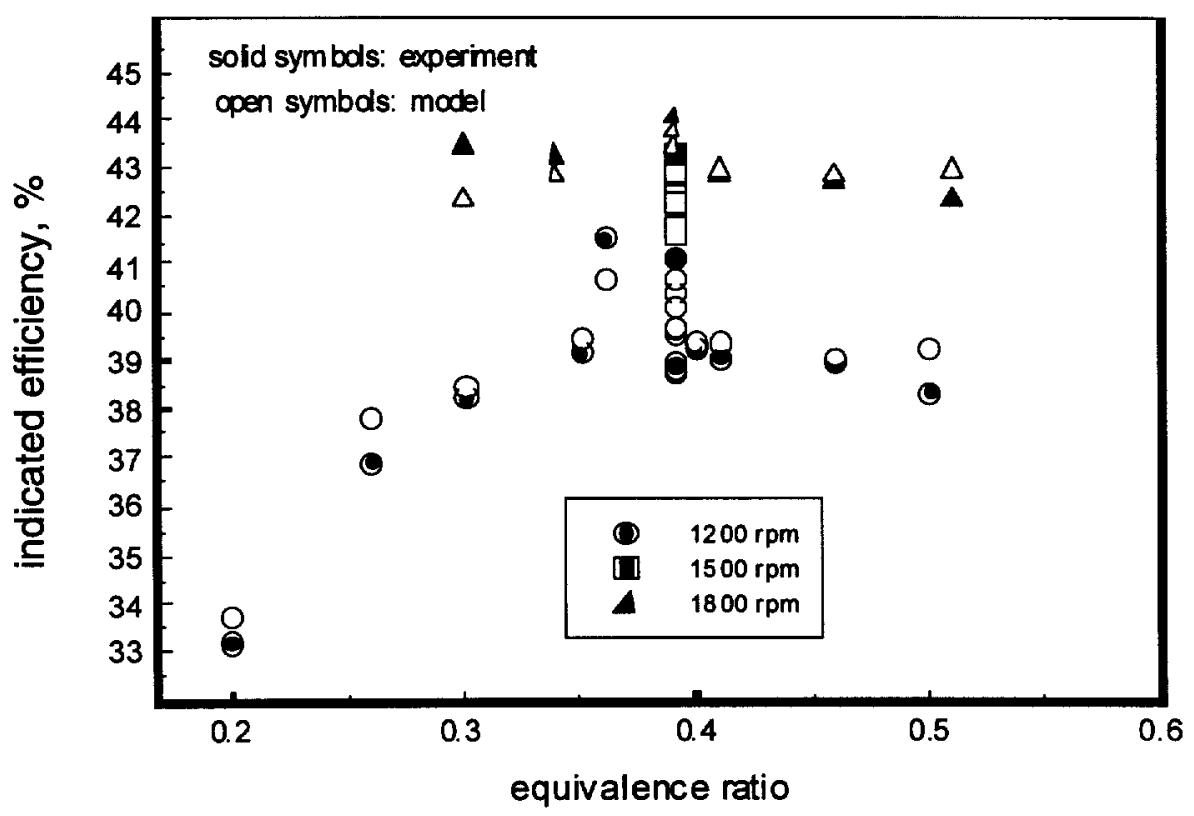

Figure 1. Indicated efficiency for the Onan engine as a function of equivalence ratio. The figure includes both the experimental results and the model predictions. 
Figure 1 shows that the model predicts absolute values as well as trends with good accuracy for engine indicated efficiency, over the whole range of operating conditions, with the maximum error of the order of $1 \%$.

No validation is done for brake thermal efficiency, because the Onan engine used in the experiment has substantially more friction per cylinder than a current automotive engine, for which the friction correlation applies.

Figure 1 shows that indicated efficiency increases as a function of engine speed, as a consequence of reduced heat transfer losses. The variation of indicated efficiency with equivalence ratio is best observed for $1200 \mathrm{rpm}$ operation, for which the greatest fuel/air range was used. Indicated efficiency reaches a maximum near a 0.40 equivalence ratio. Increasing the equivalence ratio from this point results in a decreased indicated efficiency, due to increased heat transfer and a decreased specific heat ratio $\left(\gamma=c_{p} / c_{v}\right)$ for the gas products in the cylinder [2]. Decreasing the equivalence ratio from the optimum point increases the timing losses, due to slower heat release, thereby reducing the indicated efficiency. Supercharged operation results in small indicated efficiency gains due to slightly lower heat transfer losses per unit mass of fuel at the higher densities. Supercharged operation has a larger effect on brake thermal efficiency by increasing the output work relative to the frictional work.

The engine model also includes a correlation for calculation of $\mathrm{NO}_{\mathrm{x}}$ emissions. Experimental results (Figure 2) have indicated that emissions of $\mathrm{NO}_{x}$ are mainly a function of engine equivalence ratio, being very insensitive to engine speed or intake pressure. The correlation of $\mathrm{NO}_{x}$ as a function of equivalence ratio predicts emissions accurately. The model uses a correction for supercharged and turbocharged operation, to take into account the higher intake temperature resulting from the compression process and the less than perfect effectiveness of the intercooler.

The engine model is then applied to predicting the engine performance that results if a 4-cylinder (1.97 liter) and a 3-cylinder (1.48 liter) hydrogen engines are built with the same cylinder characteristics of the Onan engine. The applicability of the 4-cylinder and 3-cylinder engines to conventional and hybrid vehicles is discussed later in this paper. The geometry and dimensions of the engine cylinders are not changed in the analysis, because small changes in geometry may result in significant changes in efficiency. It is expected, however, that larger engine cylinders will improve engine efficiency.

Using the engine model for predicting vehicle performance requires extrapolating from the engine speeds used in the experiment (1200-1800 rpm) to engine speeds that are required for vehicle operation. A maximum engine speed of $5000 \mathrm{rpm}$ is assumed. Extrapolation is done by assuming that the heat release correlations developed from the experimental data apply throughout the desired range of engine speeds, along with the previously cited volumetric efficiency assumptions. It is recognized that this extrapolation may result in errors. Errors are due to turbulence variations with engine speed which influence heat release rate, thus changing both timing losses and heat transfer losses. However, Figure 1 shows that the model predicts the efficiency trends with good accuracy for the range in which experimental data exist, and it is considered that the model can do a reasonable job at predicting efficiency for high and low engine speeds. In addition to this, engines in conventional and hybrid vehicles are most often operated at low to moderate speeds, which is the range for which the model has been validated. For the conventional and parallel hybrid vehicles analyzed in a later section of this paper the mean engine speed is $1500 \mathrm{rpm}$ for the urban cycle and $2700 \mathrm{rpm}$ for the highway cycle (see Figure 8). Maximum engine speed for the driving cycles is $3300 \mathrm{rpm}$. The series hybrid vehicle is set to operate at a constant $2400 \mathrm{rpm}$ during the driving cycles. 


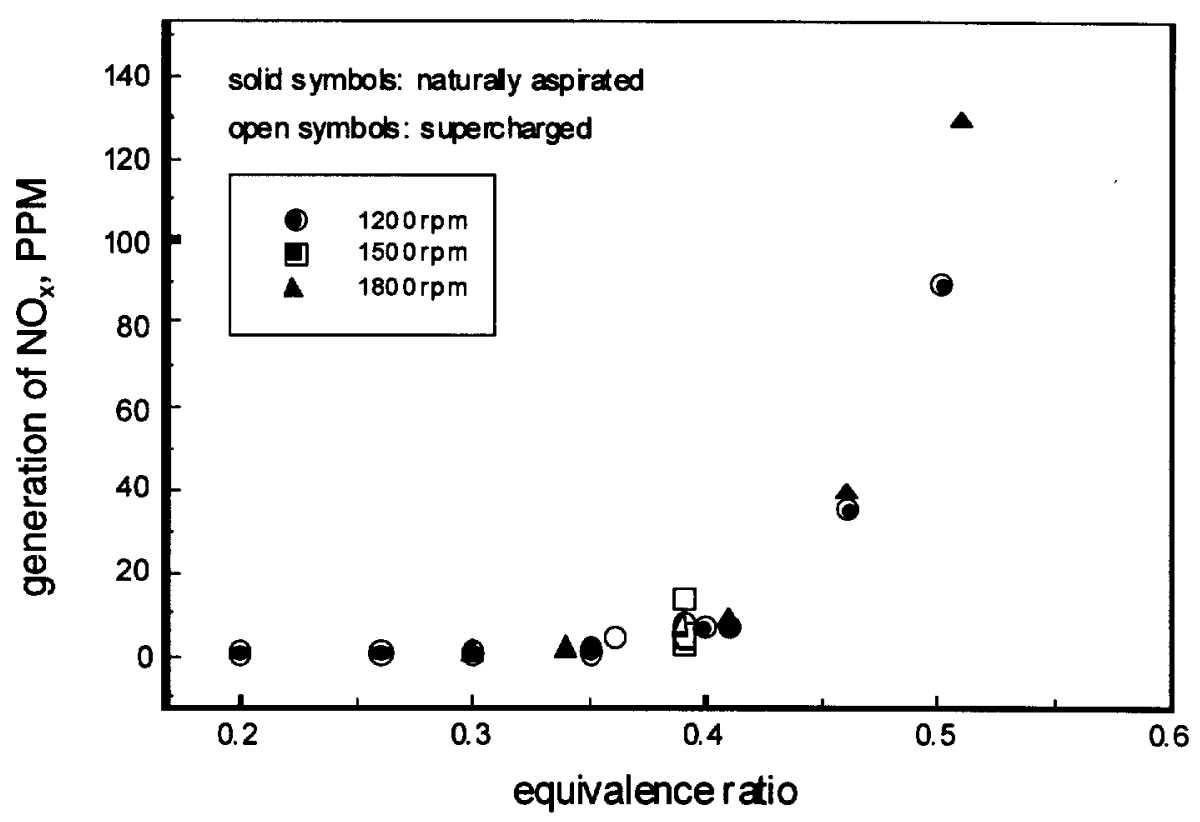

Figure 2. Emission of $\mathrm{NO}_{\mathrm{x}}$ in parts per million for the Onan engine as a function of equivalence ratio, for all the experimental points at MBT timing obtained in the analysis. Engine speeds and supercharged operation are indicated with different symbols.

Engine brake thermal efficiency is required for applying the engine code to vehicle calculations, and brake thermal efficiency is calculated with a friction and a supercharger/turbocharger model that have not been validated for this particular application. While the model cannot replace experimental runs, it is considered that the brake thermal efficiency calculated with the model gives a good idea of the performance that can be obtained with such an engine. Engine emissions are very insensitive to engine operating conditions other than maximum temperature within the cylinder, and it is therefore expected that the engine $\mathrm{NO}_{x}$ model can provide accurate predictions for emissions levels throughout the operating range.

The engine model is applied to generate engine emissions and performance maps, necessary for predicting vehicle performance. A gasoline engine has only one degree of freedom for controlling the output torque at any given speed: the inlet manifold pressure. This is due to the use of three-way catalysts that require near-stoichiometric operation for high conversion efficiency. A hydrogen engine has two degrees of freedom, because equivalence ratio can also be varied. Generating an engine map therefore requires determining a control strategy that specifies how to adjust these two parameters to obtain the desired torque for any given engine speed. In this analysis, an optimizer [8] is used to determine the combination of equivalence ratio and inlet manifold pressure that satisfies the torque requirement while providing the maximum engine brake thermal efficiency. A constraint is used in the optimization: engine $\mathrm{NO}_{x}$ emissions are less than $10 \mathrm{ppm}$ under all operating conditions. An engine generating $10 \mathrm{ppm}$ of $\mathrm{NO}_{x}$ is well below the EZEV standards (a tenth of ULEV), provided that it is installed in a vehicle with a fuel economy of $40 \mathrm{mpg}$ or higher. While emission levels for a car are set in grams per mile and not in ppm, setting a maximum allowable ppm limit guarantees that the vehicle is intrinsically an EZEV, regardless of how the vehicle is driven. 
Lean operation results in low power output, and therefore turbocharged or supercharged operation is required for providing adequate power output for the chosen displacement. Both supercharged and turbocharged operation have been considered for generating the engine performance map. The performance maps for both cases are very similar, with turbocharged operation having a slight efficiency advantage over supercharged operation. Only the results for supercharged operation are shown in this paper. Supercharged operation is preferred to turbocharged operation due to the lag time that may exist in turbocharged operation for the conventional and parallel hybrid vehicles.

Figures 3 and 4 show the predictions for engine efficiency and emissions maps, for the 4-cylinder supercharged engine. Performance maps for the 3-cylinder engines can be obtained to within a good approximation by multiplying the torque scale by $3 / 4$. Not everything scales by a factor of $3 / 4$ when the number of cylinders is decreased (for example, the number of bearings). However, the effect of these changes is small, and the scaled maps give a very good approximation for the 3-cylinder engine maps.

Figure 3 shows lines of constant brake thermal efficiency (in percent) as a function of engine speed and engine torque. The figure also shows a dotted line corresponding to the conditions at which the engine generates $10 \mathrm{ppm}$ of $\mathrm{NO}_{x}$, and a dashed line that indicates the maximum torque that can be obtained within the upper bounds of equivalence ratio (0.5) and inlet pressure ( 2 bar) used in the analysis. The $10 \mathrm{ppm} \mathrm{NO} \mathrm{x}_{\mathrm{x}}$ curve is the lower of the two, and therefore sets the limit on the maximum torque and power that can be obtained from the engine. The maximum power approaches $60 \mathrm{~kW}$ at $5000 \mathrm{rpm}$. The contour lines in this and the following figures spread beyond the $10 \mathrm{ppm}$ line, showing the potential power gains obtained by relaxing this restriction. A square in the figure indicates the approximate range of experimental conditions covered.

Figure 3 shows that the engine is predicted to have a broad area of high efficiency, for intermediate speeds and high torques. The efficiency drops for lower speeds due to increased heat transfer losses, and for higher speeds due to increased friction. As expected, the efficiency drops to zero as the load is reduced. However, the drop occurs more slowly than in conventional engines, because the equivalence ratio can be reduced as the load is reduced, resulting in lower throttling losses.

The predicted engine map is similar in shape to engine maps for recent gasoline engines (see, for example, [12]). However, engine maps are most often drawn with efficiency as a function of speed and power, so the maps presented in this paper have to be transformed before a direct comparison is possible. Current gasoline engine maps show that efficiency drops with increasing speed at low torque conditions, while Figure 3 shows that efficiency is almost independent of speed at these conditions (lower right corner of the map). These differences may be due to lower heat transfer and pumping losses in the lean-burn engine compared to the gasoline engine.

Figure 4 shows contours of $\mathrm{NO}_{\mathrm{x}}$ emissions in $\mathrm{g} / \mathrm{kWh}$ as a function of engine speed and torque. Emissions are less than $0.1 \mathrm{~g} / \mathrm{kWh}$ for most of the map, with higher emissions obtained at high speed and high torque. The line of $0.1 \mathrm{~g} / \mathrm{kWh}$ roughly corresponds to the limit of $10 \mathrm{ppm}$ at intermediate speeds. Emission levels are near zero $(<0.02 \mathrm{~g} / \mathrm{kWh})$ over the low load range, which is the range at which the engine is operated most of the time during city and highway driving in conventional and parallel hybrid cars (see Figure 8). Emissions increase slowly as the torque increases, until the restriction of $10 \mathrm{ppm}$ is approached. When this restriction is approached, the operating conditions in the engine are adjusted so that the $10 \mathrm{ppm}$ line is pushed as high as possible by increasing the manifold pressure without further increases in equivalence ratio, at the cost of some losses in efficiency. This explains the great distance between the 0.08 and the $0.1 \mathrm{~g} / \mathrm{kWh}$ curves shown in the figure. Emission levels shown in the figure are expected to be valid over the lifetime of the engine, since no catalytic converter, which may deteriorate with time, is used to control emissions. 


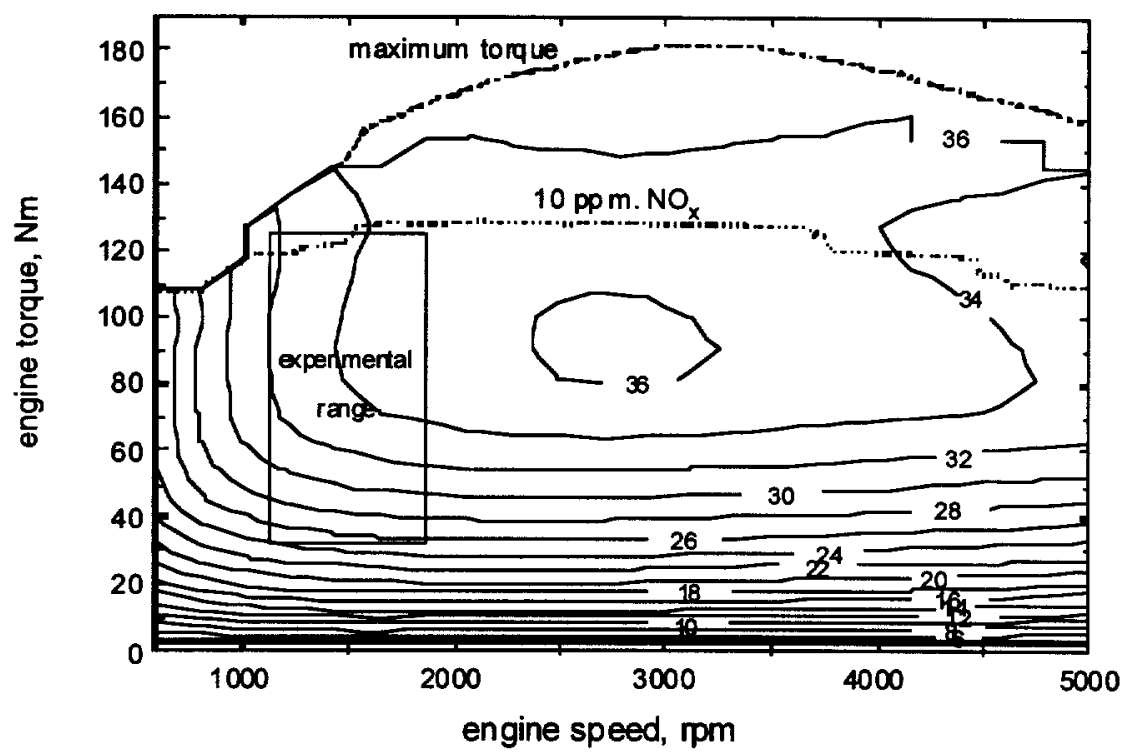

Figure 3. Contour lines of constant brake thermal efficiency (in percent) as a function of engine speed and engine torque. The dotted line corresponds to the conditions at which the engine generates $10 \mathrm{ppm}$ of $\mathrm{NO}_{x}$; the dashed line indicates the maximum engine torque that can be obtained within the constraints of maximum equivalence ratio (0.5) and inlet pressure ( 2 bar); and the square indicates the approximate area in which the experimental data were taken.

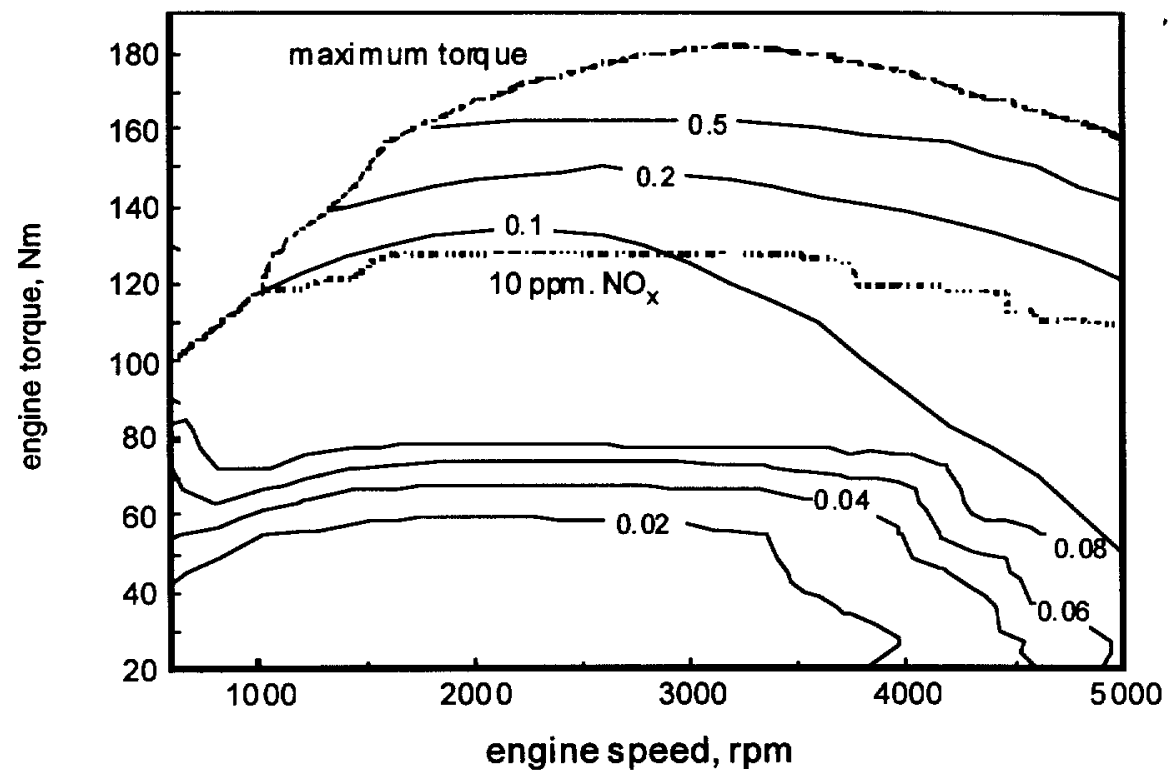

Figure 4. Contour lines of NOx emissions in $\mathrm{g} / \mathrm{kWh}$ as a function of engine speed and torque. The figure includes a dotted line for the $10 \mathrm{ppm} \mathrm{NO}$ limit, and a dashed line for the maximum engine torque that can be obtained within the constraints of maximum equivalence ratio $(0.5)$ and inlet pressure ( 2 bar) 
Intake pressure and equivalence ratio are selected by the optimizer to obtain the optimum brake thermal efficiency at every operating point. At low loads, the equivalence ratio is as low as 0.25 and the intake pressure is 0.5 bar. The equivalence ratio is reduced to keep a relatively high manifold pressure, therefore reducing pumping losses. Full information about the control strategy, including maps of equivalence ratio and intake pressure as a function of engine torque and speed, can be obtained from a previous publication [13].

\section{VEHICLE ANALYSIS}

The engine efficiency and $\mathrm{NO}_{\mathrm{x}}$ maps presented in the previous section are now used in predicting vehicle fuel economy and emissions for a conventional and parallel and series hybrid vehicles. Vehicle power train components are also selected to meet minimum performance requirements (acceleration, hill climb and range). This is accomplished by incorporating the engine maps into an existing vehicle simulation code [5].

The main characteristics of the three vehicles are listed in Table 2. All the vehicles have good aerodynamics and low rolling friction, and use a cryogenic liquid hydrogen storage. The conventional and the parallel hybrid cars use a 5-speed transmission, and the series hybrid uses a single-speed transmission. Transmission efficiency is considered independent of driving conditions. All the vehicles are required to meet the following minimum performance specifications: acceleration from 0 to $97 \mathrm{~km} / \mathrm{h}$ $(0-60 \mathrm{mph})$ in no more than 10 seconds; climbing a slope of at least $6 \%$ at a constant $97 \mathrm{~km} / \mathrm{h}(60 \mathrm{mph})$ speed with a $272 \mathrm{~kg}$ payload; and minimum range of $483 \mathrm{~km}$ (300 miles).

Both hybrid vehicles use a flywheel for energy storage. A flywheel is selected because it has the potential of providing a high efficiency and power output. A detailed model of a flywheel has been developed. This model includes a performance map of efficiency as a function of state of charge and power output, as well as a correlation of stand-by losses as a function of state of charge.

A brief description of the operating strategies for the parallel and series vehicles is as follows: The parallel hybrid vehicle operates very similarly to a conventional car, except that a flywheel and a traction motor are used for complementing the power of the engine during sudden accelerations, and for regenerative braking. The use of the flywheel for power peaking allows a reduction in the size of the engine, which may therefore operate more efficiently than the engine used in the conventional car at the low-power conditions that constitute most of the urban and highway driving cycles. The engine is sized to provide the required performance during long hill climbs, for which the flywheel cannot provide the required energy. A low-capacity, low-power flywheel is enough for this application. The control strategy used for the flywheel consists of keeping it near $50 \%$ state of charge. In this way, the flywheel is always ready to provide energy for a sudden acceleration, and to absorb energy during regenerative braking. It is noted that there are many possible parallel hybrid control strategies. The $50 \%$ state of charge for the flywheel is chosen as a simple strategy that accomplishes both engine downsizing and regenerative braking. It is likely that better parallel strategies may exist.

The series hybrid vehicle operates with an engine in an on-off mode, with no mechanjical link between the engine and the wheels. An electric motor provides all tractive power. When the engine is running, it drives a generator that supplies electricity to both the electric motor and an energy storage system. A flywheel is used for energy storage. When the storage system is fully charged, the engine is turned off, and the storage system provides all the energy required for traction and accessories. Series hybrid vehicles have high fuel economy because the engine is operated at a high efficiency condition without ever idling. Spark ignition engines can be run unthrottled thus avoiding pumping losses. Engines in series hybrids operate most of the time at a low power, high efficiency condition, at constant speed and load. When additional power is required during long hill climbs, the engine can be operated at a high power level, possibly at a lower efficiency. The flywheel provides the power for sudden accelerations, and the engine is sized for providing the required performance for long hill 
climbs. On-off engine operation results in decreased engine efficiency, due to the repeated engine cold starts. This reduction in efficiency is taken into account in this analysis by introducing an energy penalty (10 Wh) every time the engine is restarted. This is done to account for increased friction due to engine cold operation. Emissions are not expected to increase considerably due to on-off engine operation because no catalytic converter is used to control emissions.

Table 2. Main parameters for hydrogen-fueled conventional, parallel hybrid and series hybrid vehicles.

Vehicle parameter

frontal area, $\mathrm{m}^{2}$

aerodynamic drag coefficient

coefficient of rolling friction

transmission efficiency

transmission gears

accessory load, $\mathrm{W}$

engine idling speed, rpm

launch engine RPM, maximum effort acceleration

regenerative braking

fraction of available energy recovered by regen.

braking, $\%$

maximum one-way flywheel efficiency, \%

generator type

motor type

energy storage device

hydrogen storage conventional parallel series hybrid

$\begin{array}{lll}2.04 & 2.04 & 2.04 \\ 0.24 & 0.24 & 0.24 \\ 0.007 & 0.007 & 0.007 \\ 0.94 & 0.94 & 0.95 \\ 5 & 5 & 1 \\ 1000 & 1000 & 1000 \\ 600 & 600 & - \\ 3600 & 3600 & - \\ \text { no } & \text { yes } & \text { yes }\end{array}$

$\begin{array}{lll}- & 70 & 70\end{array}$

- $96 \quad 96$

- permanent permanent magnet magnet

$A C$ induction $A C$ induction flywheel flywheel liquid liquid

The results of the analysis are listed in Table 3 . Empty weight is set to $1000 \mathrm{~kg}$ for the conventional car, which is used as base case. This low weight is chosen because research programs such as PNGV (Partnership for a New Generation of Vehicles) are likely to result in weight reductions for future cars. Weight for the other two vehicles is calculated by replacing components, and adding or subtracting the weight of the components. A $30 \%$ structural penalty is added to the difference in power train weight, to take into account the need for a heavier structure that results from a heavier power train. The parallel hybrid car has almost the same weight as the conventional car. The weight of the added components (flywheel and motor) is compensated by the reductions in weight that result by downsizing the engine, transmission and hydrogen tank. The series hybrid vehicle weighs about $100 \mathrm{~kg}$ more than the other two vehicles, primarily due to its need for a flywheel with greater energy storage capacity.

The conventional vehicle requires a 4-cylinder engine to provide the required acceleration performance. This engine is therefore oversized for providing the required hill climbing performance $(12.8 \%$ instead of $6 \%$ ). The hybrid vehicles only require a 3-cylinder engine, since the flywheel can be used for providing the power for maximum effort acceleration. Engines for the hybrid vehicles are sized for the hill climb requirement. However, the previously imposed restriction of keeping the cylinder size and geometry constant in the analysis results in an oversized engine for the parallel hybrid. It would be necessary to reduce the size of the individual cylinders to exactly obtain the specified hill climb performance. The mass of hydrogen in the tank (and therefore the mass and volume of the hydrogen tank) is adjusted to meet the desired range. The internal tank volume for the conventional car is about 100 liters ( 27 gal) [14]. The parallel hybrid only requires a $20 \mathrm{~kW}, 0.2 \mathrm{kWh}$ flywheel for power augmentation, compared to $100 \mathrm{~kW}$ and $1 \mathrm{kWh}$ for the series hybrid. 
Table 3. Results of the analysis for the conventional, parallel hybrid and series hybrid hydrogen-fueled vehicles.

Vehicle parameter

test weight, (empty weight $+136 \mathrm{~kg}$ )

number of engine cylinders

engine displacement, liters

hydrogen tank storage capacity, $\mathrm{kg}$

motor maximum short-term torque, $\mathrm{Nm}$

motor maximum speed, rpm

flywheel energy storage, kWh

flywheel maximum power, $\mathrm{kW}$

average engine efficiency, urban cycle, $\%$

average engine efficiency, highway cycle, $\%$

fuel economy ${ }^{1}$, urban cycle, $\mathrm{km} / \mathrm{liter}$ ( $\mathrm{mpg}$ )

fuel economy ${ }^{1}$, highway cycle, km/liter (mpg)

fuel economy ${ }^{1}$, combined cycle, $\mathrm{km} / \mathrm{liter}$ (mpg)

$\mathrm{NO}_{x}$ emissions, urban, $10^{-3} \mathrm{~g} / \mathrm{km}\left(10^{-3} \mathrm{~g} / \mathrm{mile}\right)$

time for 0-97 km/h (0-60 mph), s

max. climbing slope at $97 \mathrm{~km} / \mathrm{h}(60 \mathrm{mph}), \%$

vehicle range, combined cycle, $\mathrm{km}$ (miles) conventional parallel hybrid series hybrid

$\begin{array}{lll}1136 & 1127 & 1238 \\ 4 & 3 & 3 \\ 1.97 & 1.479 & 1.479 \\ 7.2 & 5.7 & 4.8 \\ - & 48 & 190 \\ - & 11000 & 11000 \\ - & 0.2 & 1 \\ - & 20 & 100 \\ 21.4 & 21.9 & 36 \\ 22.7 & 25.7 & 36 \\ 15.2(35.8) & 20.0(47.0) & 24.4(57.4) \\ 22.0(51.8) & 26.5(62.4) & 29.8(70.0) \\ 17.7(41.6) & 22.5(52.9) & 26.6(62.5) \\ 2.08(3.35) & 2.24(3.61) & 12.4(20.0) \\ 10.0 & 10.0 & 10.0 \\ 12.8 & 9.0 & 6.0 \\ 483(300) & 483(300) & 483(300)\end{array}$

Fuel economy is listed in the table in gasoline-equivalent units. Fuel economy for the series hybrid is highest because the engine always operates at peak efficiency (36\%). The difference in fuel economy between the parallel hybrid and the conventional car is due in part to the higher average engine efficiency that results from downsizing the engine, and in part due to the regenerative braking that can be done in the hybrid.

While all vehicles have a high fuel economy, the fuel economy of the series hybrid vehicle is lower than the $33.5 \mathrm{~km} / \mathrm{l}(79 \mathrm{mpg})$ predicted for a hydrogen series hybrid vehicle in a previous work by the authors [5]. The results are different because the engine model used in this analysis is based on experimental data for a particular engine (Onan), while the previous work indicates improvements that are likely to be obtained in a future optimized hydrogen engine.

The most desirable feature of the vehicles analyzed in this paper is their low emissions. Emissions are measured only during the urban cycle for EPA certification. Therefore only these values are reported in Table 3. The conventional car has the lowest emission levels. Emissions for the conventional car are projected to be a factor of 60 lower than the CARB ULEV requirements, and therefore a factor of 6 lower than EZEV. The reason for the emissions to be so low is that the engine is operated most of the time at low torque, generating much less than the $10 \mathrm{ppm}$ maximum allowable $\mathrm{NO}_{\mathrm{x}}$ (Figure 8 ). Emissions out of the parallel hybrid vehicle are slightly higher than the conventional car, because the downsized engine has to operate at a higher load. The series hybrid vehicle operates at peak efficiency, which occurs near the limit of $10 \mathrm{ppm}$ of $\mathrm{NO}_{\mathrm{x}}$. Emissions out of the series hybrid engine are therefore higher than for the other two vehicles, exactly at the EZEV limits. Emissions out of the series hybrid could be reduced by changing the engine operating conditions, at the cost of a slight loss in efficiency, to allow for a margin of error during the certification process. 


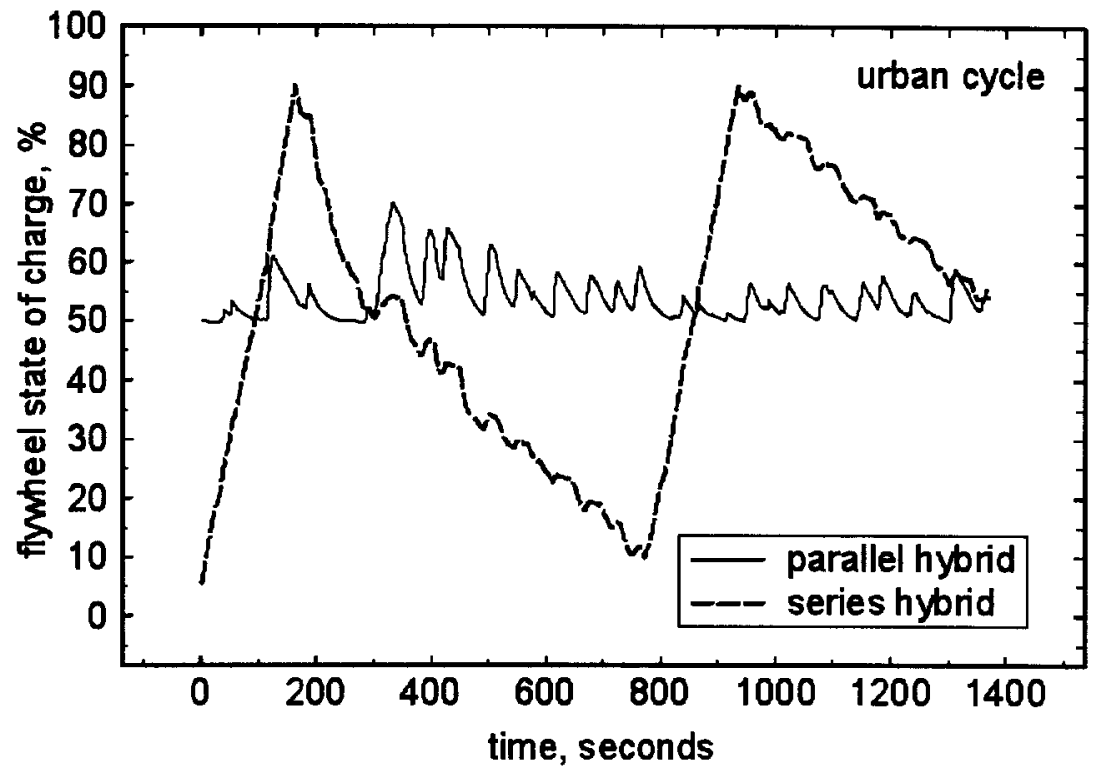

Figure 5. Flywheel state of charge for the series hybrid and the parallel hybrid vehicles along the urban driving cycle. For the series hybrid, the engine runs at constant power until it fully charges the flywheel. For the parallel hybrid, the flywheel is kept at about $50 \%$ state of charge, ready to store energy during regenerative braking, or provide energy for a sudden acceleration.

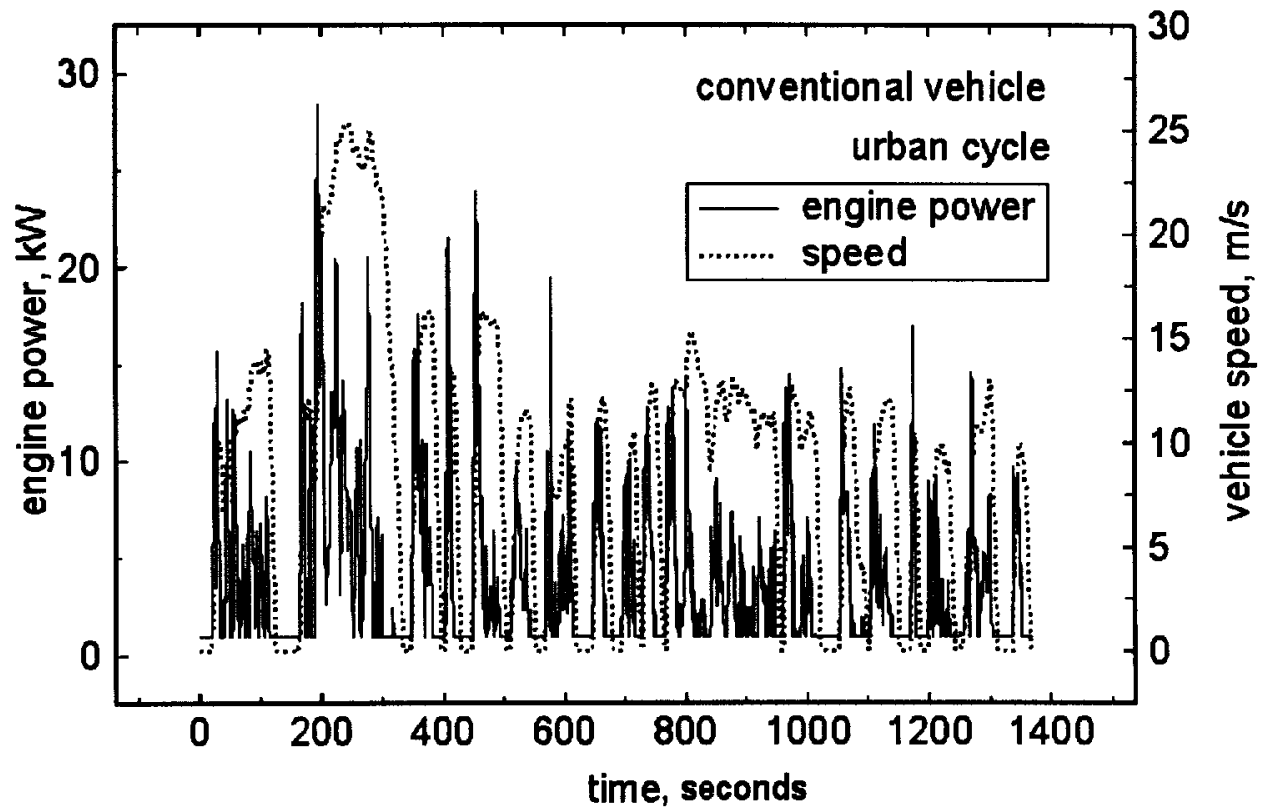

Figure 6. Engine power for the conventional vehicle during the urban cycle. The driving cycle speed is indicated by a dotted line. 


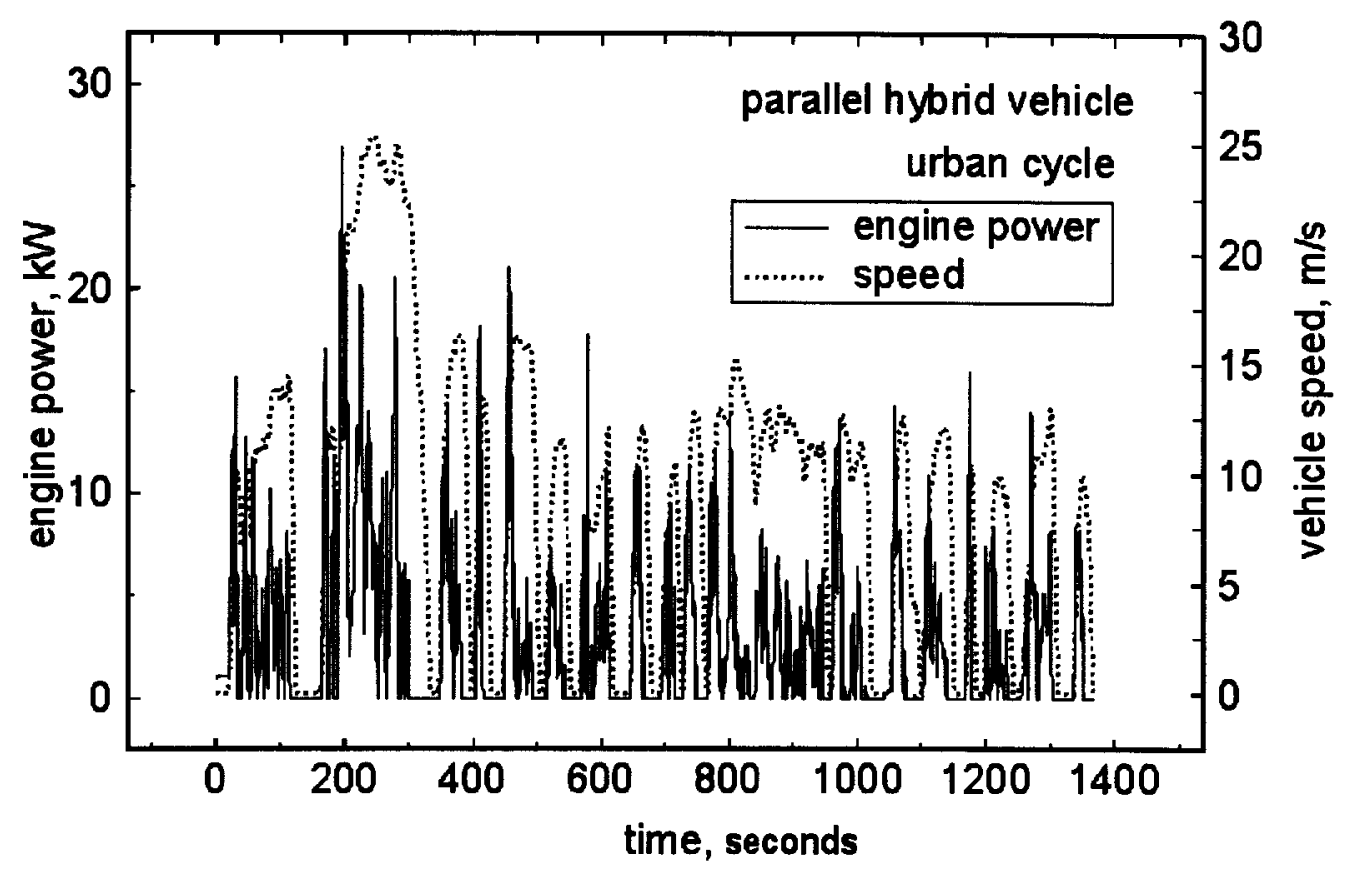

Figure 7. Engine power output for the parallel hybrid vehicle. The driving cycle speed is indicated by a dotted line.

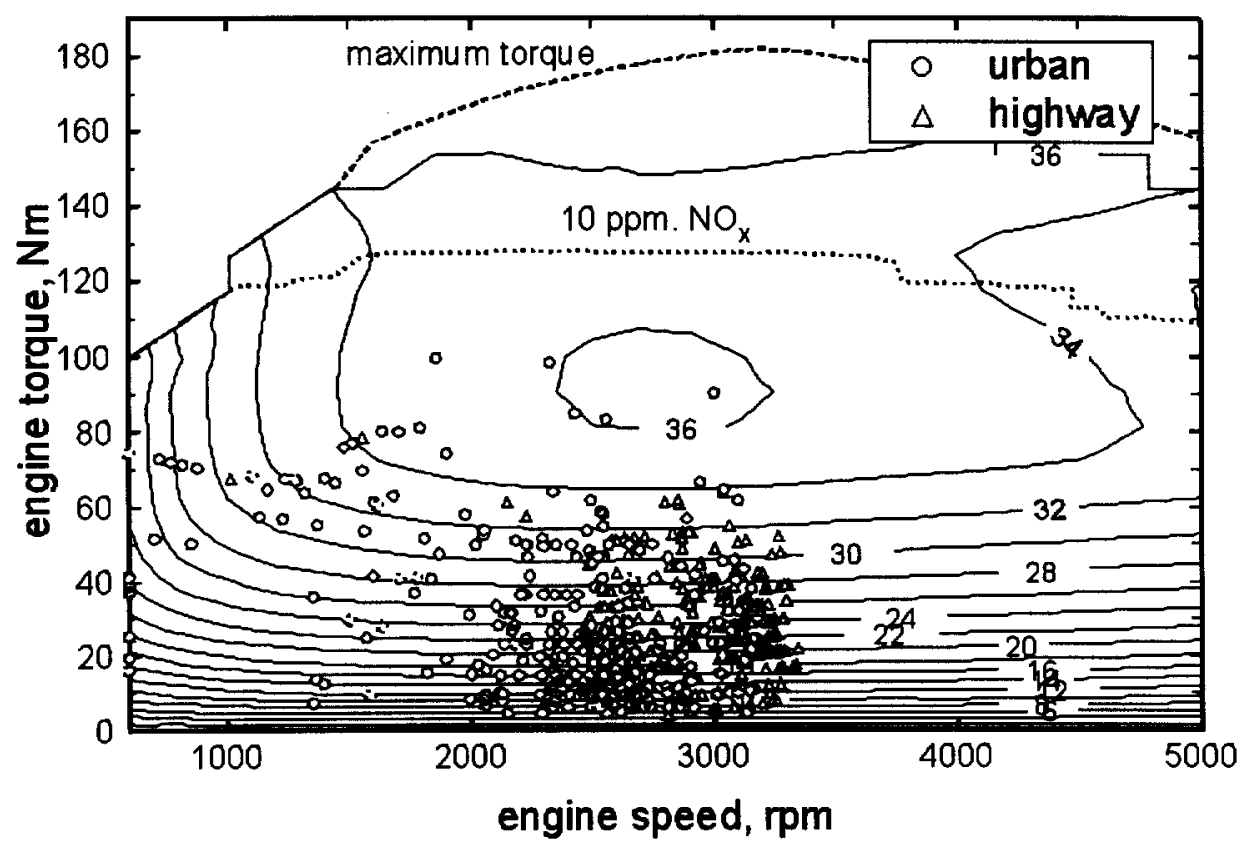

Figure 8. A representative set of engine operating points for the conventional car, for both the urban and highway cycles, superimposed on the engine efficiency map (repeated from Figure 3 ). 


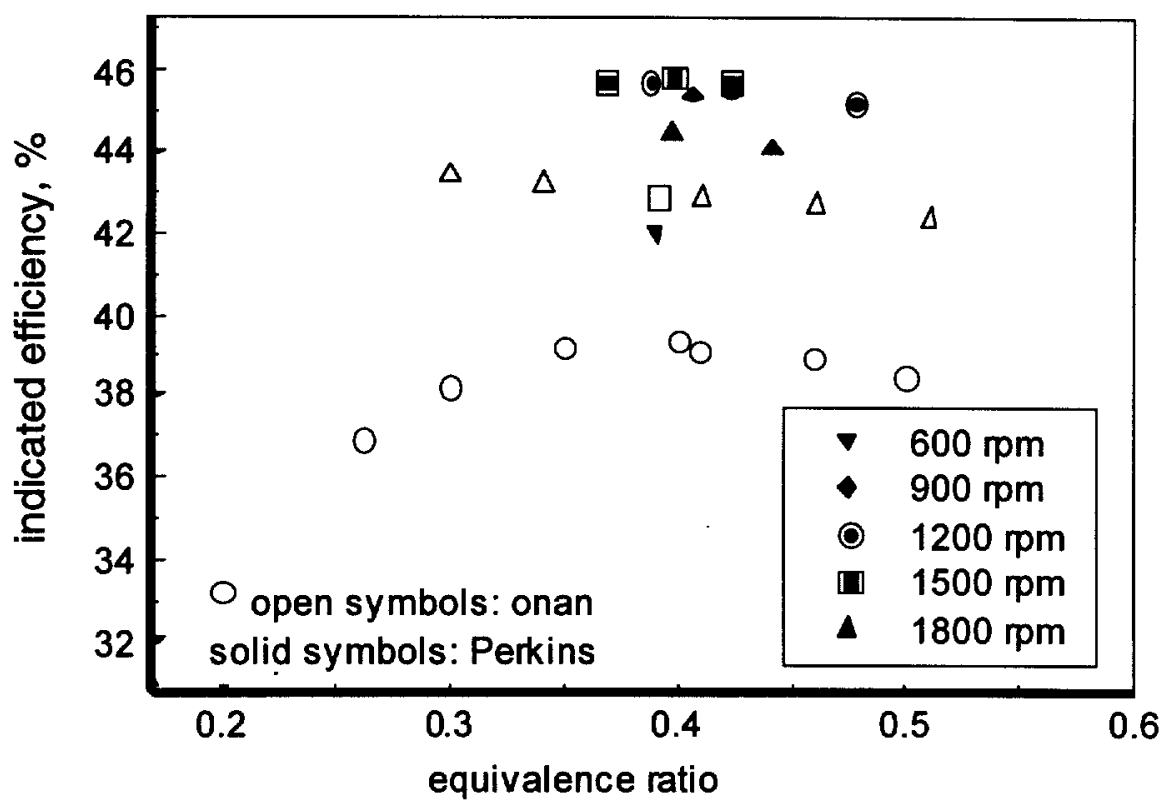

Figure 9. Indicated efficiency as a function of equivalence ratio and engine speed for the Perkins engine (solid symbols) and the Onan engine (open symbols, repeated from Figure 1 for comparison).

Two important facts should be emphasized about the emissions generated by these vehicles. First, no catalytic converter is required, and therefore emissions do not increase during the life of the car due to catalytic converter or emissions control system failure. Second, emissions are intrinsically low. No

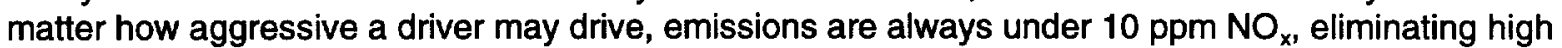
off-cycle emissions that are common in gasoline cars.

Figures 5, 6, 7 and 8 are used to illustrate some of the results. Figure 5 shows flywheel state of charge for the series hybrid and the parallel hybrid vehicles along the urban driving cycle. For the series hybrid, the engine runs at constant power until it fully charges the flywheel, which takes about 180 seconds. The flywheel then provides all the energy requirements, discharging in about 600 seconds. The engine is then turned on again to repeat the cycle. For the parallel hybrid, the flywheel is kept at about $50 \%$ state of charge, ready to store energy during regenerative braking, or provide energy for a sudden acceleration. The flywheel state of charge increases due to regenerative braking, and drops when power is extracted from the flywheel. Flywheel stand-by losses are projected to be of the order of $80 \mathrm{~W}$ and also tend to reduce the state of charge.

Figure 6 shows engine power for the conventional vehicle during the urban driving cycle. The driving cycle speed is indicated by a dotted line. Minimum engine power output is $1000 \mathrm{~W}$, due to the need to provide for accessories. Figure 7 shows the nearly identical engine power output for the parallel hybrid vehicle. Power out of the two engines is very similar, except that peak power out of the parallel hybrid is reduced by 1 to $3 \mathrm{~kW}$ due to the power provided by the flywheel. Another difference between the output powers is that minimum power out of the parallel hybrid engine is zero, since the flywheel can now provide the accessory loads. 
Figure 8 shows a representative set of engine operating points for the conventional car, for both the urban and highway cycles, superimposed on the engine efficiency map (repeated from Figure 3). The points indicate that the engine operates at low torque during most of the time, therefore generating very low emissions. Efficiency could be improved by relaxing the $10 \mathrm{ppm} \mathrm{NO} \mathrm{N}_{\mathrm{x}}$ emission limit, and this limit could be relaxed while still achieving EZEV levels. However, a vehicle that can emit more than $10 \mathrm{ppm}$ of $\mathrm{NO}_{x}$ would not be intrinsically an EZEV, and would generate high $\mathrm{NO}_{x}$ if driven aggressively at high torque.

\section{EXPERIMENTAL HYDROGEN ENGINE EVALUATION UPDATE}

An experimental evaluation of a new hydrogen engine (Perkins) has been recently done [4]. The main characteristics of this engine are listed in Table 4. The cylinder is bigger than for the Onan engine (834 $\mathrm{cm}^{3}$ compared to $493 \mathrm{~cm}^{3}$ ), therefore reducing heat transfer losses. Preliminary results are shown in Figure 9, which gives indicated efficiency as a function of equivalence ratio and engine speed for the Perkins engine and the Onan engine (repeated from Figure 1 for comparison). The indicated efficiency for the Perkins engine is higher than for the Onan engine, and it is very insensitive to equivalence ratio and engine speed. Future runs will attempt to increase the engine efficiency by optimizing the turbulence within the cylinder to minimize heat transfer and timing losses.

Table 4. Perkins engine characteristics and experimental conditions.

Bore, $\mathrm{mm}$

91.44

Stroke, $\mathrm{mm}$

127.0

Displacement, $\mathrm{cm}^{3}$

834.0

Geometric compression ratio

14.04:1

Experimental range for equivalence ratio

$0.36-0.47$

Experimental range for engine speed, rpm

$600-1800$

Experimental range for volumetric efficiency, \%

$90-110$

\section{CONCLUSIONS}

This paper presents the development and validation of a time-dependent engine model, and its application to conventional and hybrid vehicles. The engine model is applied to a hydrogen engine which has been experimentally tested. The model predicts accurately engine efficiency and $\mathrm{NO}_{\mathrm{x}}$ emissions over the full range of experimental operating conditions. The validated model is then used to generate engine performance and emission maps for supercharged engine operation. The performance maps are then incorporated into a vehicle evaluation code to obtain performance and emissions for hydrogen-fueled conventional, parallel and series hybrid vehicles. All vehicles are specified to meet minimum acceleration, hill climb and range requirements that make them comparable to current automobiles. Analysis of these vehicles yields the following results:

1. Emissions out of the conventional car are projected to be a factor of 60 lower than the CARB ULEV requirements, and therefore a factor of 6 lower than EZEV. The engine control strategy presented in this paper guarantees that the conventional vehicle achieves EZEV emissions levels regardless of how the car is driven. The conventional vehicle also has a high fuel economy.

2. The parallel hybrid vehicle uses a downsized engine and a small flywheel for power augmentation and regenerative braking. Emissions are also well within EZEV range. Fuel economy falls between the conventional and the series hybrid cars. 
3. The series hybrid vehicle has the highest fuel economy. Emissions are higher than for conventional cars, at the EZEV limits. Emissions in a series hybrid vehicle are intrinsically independent of driver's input.

These results indicate that lean-burn hydrogen spark-ignited engines are an alternative to providing EZEV emissions, while at the same time providing a range, acceleration and hill climbing performance comparable to conventional cars. These vehicles are intrinsically EZEV, since emissions are not controlled with a catalytic converter that may degrade, and are also independent of the driving habits of the driver.

Work performed under the auspices of the U.S. Department of Energy by Lawrence Livermore National Laboratory under Contract W-7405-ENG-48.

\section{REFERENCES}

1. Smith, J.R., 1994, "Optimized Hydrogen Piston Engines," Proceedings of the 1994 International Congress on Transportation Electronics, Convergence 1994, SAE, pp. 161-166.

2. Heywood, J.B., 1988, Internal Combustion Engine Fundamentals, McGraw-Hill, New York.

3. California Air Resources Board, Mobile Sources Division, 1995, "Proposed Amendments to the LowEmission Vehicle Regulations to Add an Equivalent Zero-Emission Vehicle (EZEV) Standard and Allow Zero-Emission Vehicle Credit for Hybrid Electric Vehicles," Preliminary Draft Staff Report, CARB, EI Monte, CA, July 14.

4. Van Blarigan, P., 1996, "Development of a Hydrogen-Fueled Internal Combustion Engine Designed for Single Speed/Power Operation," Proceedings of the 1996 SAE Future Transportation technology Conference and Exposition, Vancouver, BC.

5. Aceves, S.M., and Smith, J.R., 1995, "A Hybrid Vehicle Evaluation Code and Its Application to Vehicle Design," SAE paper 950491.

6. Pehr, K., 1996b, "Aspects of Safety and Acceptance of LH2 Tank Systems in Passenger Cars," International Journal of Hydrogen Energy, Vol. 21, pp. 387-395.

7. Ferguson, C.R., 1986, "Internal Combustion Engines, Applied Termosciences," John Wiley and Sons, New York.

8. Haney, S.W., Barr, W.L., Crotinger, J.A., Perkins, L.J., Solomon, C.J., Chaniotakis, E.A., Freidberg, J.P., Wei, J., Galambos, J.D., and Mandrekas, J., 1992, "A SUPERCODE for Systems Analysis of Tokamak Experiments and Reactors," Fusion Technology, Vol. 21, p. 1749.

9. Woschni, G., 1967, "Universally Applicable Equation for the Instantaneous Heat Transfer Coefficient in the Internal Combustion Engine," SAE Paper 670931.

10. Patton, K.J., Nitschke, R.G., and Heywood, J.B., 1989, "Development and Evaluation of a Friction Model for Spark-Ignition Engines," SAE Paper 890836.

11. Olsson K., and Johansson, B., 1995, "Combustion Chambers for National Gas SI Engines Part 2: Combustion and Emissions," SAE paper 950517.

12. Thomson, M.W., Frelund, A.R., Pallas, M., and Miller, K.D., 1987, "General Motors 2.3L Quad 4 Engine," SAE Paper 870353.

13. Aceves, S.M., and Smith, J.R., 1996, "Lean-Burn Hydrogen Spark-Ignited Engines: The Mechanical Equivalent to the Fuel Cell," Proceedings of the $18^{\text {th }}$ Annual Fall Technical Conference of the ASME 
14. Internal Combustion Engine Division, ICE-Vol. 27-3, Alternative Fuels, Edited by J.A. Caton, pp.23-32. 15. Peschka, W., 1998, "Liquid Hydrogen, Fuel of the Future," Springer-Verlag, Vienna, Austria. 


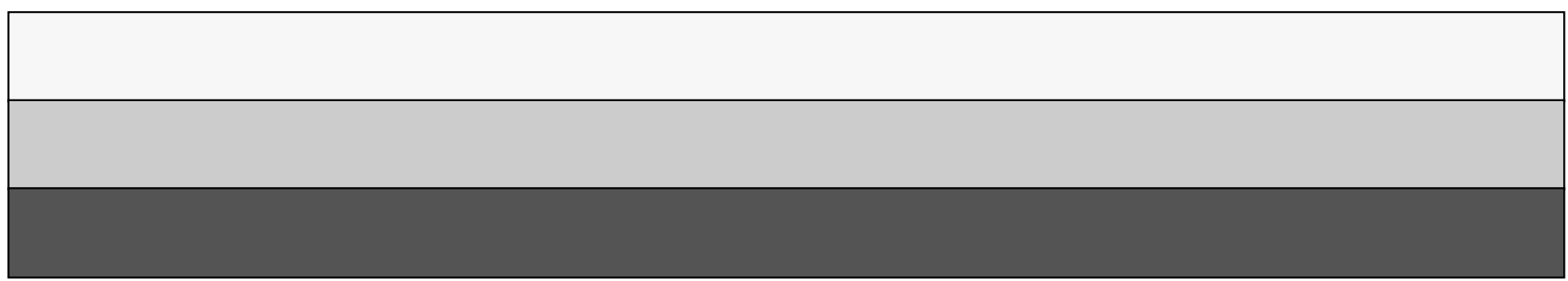

